Original Article

\title{
SCREENING AND CHARACTERISTIC STUDY OF ANTIMICROBIAL ACTINOMYCETES FROM NEAR-BY SOIL OF MEDICINAL PLANTS
}

\author{
RAM DARSHIT ${ }^{*}$, DR. DEVANG PANDYA ${ }^{2}$ \\ ${ }^{1}$ Assistant Professor, Noble Pharmacy College, Junagadh, Gujarat and PhD Research Scholar, RK University, Rajkot, Gujarat, India, ${ }^{2} \mathrm{Dy}$. \\ Director, School of Pharmacy, RK University, Rajkot, Gujarat, India \\ Email: dramahir@gmail.com \\ Received: 11 Aug 2018 Revised and Accepted: 04 Oct 2018
}

\section{ABSTRACT}

Objective: Isolation and characterization study of actinomycetes from soil near medicinal plants in saurashtra region of Gujarat which can produce antimicrobial compounds.

Methods: Present study 11 different medicinal plants 3 regions of saurashtra selected. Microflora part of soil was used. Different media used for isolation. Microscopic methods used for Study of colony characteristics, arial and vegetative mycelium color and morphological examination of isolates. Primary screening was done by using cross streak method while for secondary screening well diffusion techniques with thin layer chromatography and bioautography. Antimicrobial activity of most potent isolates check against test organisms. Different biochemical methods used for characterization of the most active isolate.

Results: It was found that out of 66 actinomycetes isolates 45 (68.2 \%) actinomycetes isolates were showing activity against test microbes. In the primary screening, 15 actinomycets isolates showed good antimicrobial activity. Out of these 15 actinomycetes isolates 5 isolates GOS1, J0S1, GOS3, GTF1 and JTF1 showing a broad spectrum of activity against microorganisms. It was found that out of this 5 isolates GOS1 was most potent antagonistic actinomycetes. Characterizations, as well as optimization studies of actinomycetes, isolates GOS1 which may use to produce new and useful antimicrobial compounds and other metabolites.

Conclusion: It was concluded that actinomycetes isolates from different soil samples nearby medicinal plant area of saurashtra region are a good source to produce many useful antimicrobial compounds and other metabolites.

Keywords: Actinomycets, Mycelium, Antimicrobial, Isolate, Metabolites

(C) 2018 The Authors. Published by Innovare Academic Sciences Pvt Ltd. This is an open access article under the CC BY license (http://creativecommons.org/licenses/by/4.0/] DOI: http://dx.doi.org/10.22159/ijpps.2018v10i11.29068

\section{INTRODUCTION}

In the last few years, resistance against medicine is developed by microorganisms very rapidly increased. Some microorganisms developed resistance against multidrug also so now a day's global health sector face this big obstacle for treatment of various diseases with many antibiotics and other importance metabolites. Meanwhile, developments of new and effective medicine against those microorganisms are very difficult and slow in rate. So there are focused on developed microorganisms from which we can obtain new and useful substances against various resistance microorganisms. In his situation, we are looking after many environmental sources from where we found many new species of microorganisms and use those species to develop many importance substances. So the need of new microbial species is very important in respect to overcome these major healthcare issues. In the development of such compounds who have antimicrobial activity and also other industrially important metabolites, natural sources played a vital role. Amongst all sources soil is the most important source from where we can develop antimicrobial compounds and other metabolites also [1].
Soil is the reservoir of so many types of microbial species on earth. Ultimately soil is a very rich source of diverse microbes. Locality and climate is the main factor affecting on microorganism amount and proposition of microorganisms. Microorganism are developed and grow excellently in soil here soil is perfect media for them. Soil is like one living system for those species. There are many types of microorganisms are there amongst them bacteria, virus, fungi, and actinomycetes are major groups. Microbial population is very high in the topmost layer of soil surface up to $30 \mathrm{~cm}$ depth also known as horizon A and population of microorganisms is decreases as soil depth. According to the type of soil those microbes are varied in respect to number and type also like sandy soil, red rock soil fallow land soil, etc. Soil flora is one of the main groups of living organisms in the soil in this group bacteria, algae, actinomycetes, and fungi is observed [2].

Actinomycetes are the main source from which most of the antibiotics are developed. They are gram-positive bacteria having various microorganisms with characteristics like unicellular and branching in nature. Actinomycetes are mainly produced two type of mycelium first is a substrate, and other is aerial [3].

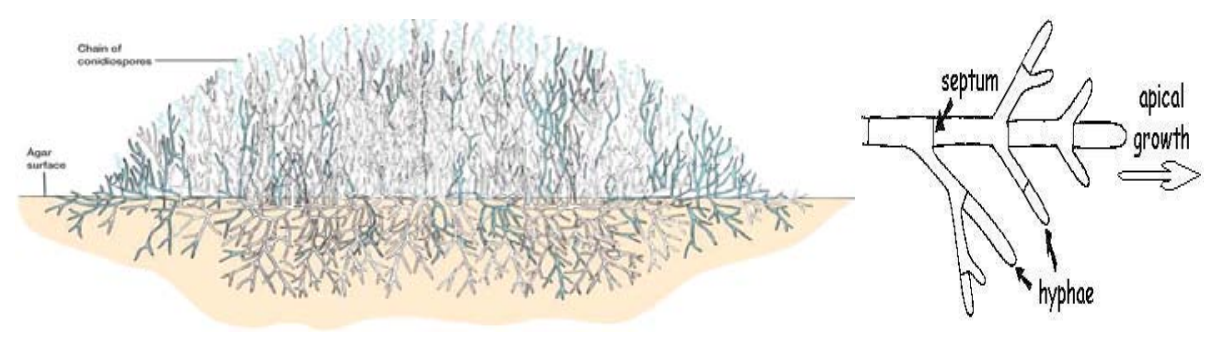

Fig. 1: (A) Agar surface view of the colony [4] (B) Fungi like hyphae and conidia [4] 
Number of antibiotics produced by a major group of microorganisms Taxonomic group bacteria other than actinomycetes produce around 950 numbers of antibiotics, Actinomycetes produce around 4600 number of antibiotics and fungi produce around 1600 numbers of antibiotics. This Represents that most of the drug mainly produced by Actinomycetes [4].

\section{MATERIALS AND METHODS}

\section{Selection of area}

In our study, we have selected randomly three regions of Saurashtra Rajkot, Junagadh, and Gir Somnath.

\section{Selection of places}

Places are selected randomly for the collection of samples Agriculture university gardens, Junagadh, Girnar forest, junagadh, the Herbal garden of RK University, Rajkot, Plant Nursery in talala gir forest and Plant nursery in Mangrol.

\section{Selection of soil area around plants}

Area around Plants selected on the basis of probability to getting actinomycetes which having antimicrobial activity. Aloe vera, Azadirachta indica, Syzygium cumini, Datura stramonium, Rosa indica, Pongamia pinnata, Oscimum sanctum, Allium sativum, Allium cepa, Trigonella foenum-graecum, Psoralea corylifolia.

\section{Selection of soil part}

Soil sample will be collected from microflora part of the soil. This part has a maximum number of microorganisms in the soil. Separate up $3 \mathrm{~cm}$ soil from the surface than up to $20 \mathrm{~cm}$ depth part (which is microflora part) of soil will be select for sample collection. Collection of soil samples sterile tubes, sterile stainless steel spatula, shovel, and scoops used [5].

\section{Soil sampling and treatment with a sample}

These samples collected on sterile tubes and airtight immediately after collection of samples. Care must be taken while collection and transportation of the samples to reduce contamination of the samples. Soil samples air dried at room temperature in laminar air flow for one day and stored at $4{ }^{\circ} \mathrm{C}$ until further process [6].

For dilution of the sample, each glassware and articles are previously sterile by autoclave. Take $99 \mathrm{ml}$ sterile water and $1 \mathrm{gm}$ of soil is added into water in conical flask and shake flask for 1-2 h in rotary shaker thereafter take $1 \mathrm{ml}$ from the flask by sterile pipette and added in sterile test tube for with $9 \mathrm{ml}$ sterile water and vortex for 10 minute and then serially take $1 \mathrm{ml}$ from each test tube follow same procedure and make aliquots of $0.1 \mathrm{ml}$ from each dilutions.

After sterilization of the media antifungal Nystatin was added (50 $\mu \mathrm{g} / \mathrm{ml}$ ) then media were poured into Petri dishes under sterile condition (laminar air flow) and allow cooling for sufficient time for solidification of media. The diluted soil samples were taken $0.1 \mathrm{ml}$ quantity and spread on the three of the media with the help of sterile bent glass road and kept at $28^{\circ} \mathrm{C}$ for $1 \mathrm{w}$, and microbe's growth was observed every day. Then developed colonies of actinomycetes were taken and make a pure colony in media which used in the development of the colony by using streak plate method. Three types of media are used for isolation of soil samples Starch Casein Agar Media, Yeast Mannitol Agar Media and Nutrient Agar media [7, 8].

\section{Study of characteristics of isolates}

\section{Actinomycetes isolate their colony and morphological characteristics}

After typical incubation colonies of actinomycetes were selected then aerial and vegetative mycelium (reverse side) color was studied.

As per colony appearance find out colonies of actinomycetes in media plate from other microorganisms colonies $[9,10]$. In respect to colonies of actinomycetes, there were a compact and conical appearance as well as leathery appearance and dry surface is observed. By using 11 plant soil and three regions of saurashtra area, we got total 66 actinomycete isolates.

\section{Microscopic examination}

By using a method which is known as coverslip culture and observed substrate mycelium whether it is present or not. Observed the fragments are there or not in respect to substrate mycelium. Also, sponrangia and sclerotia are present of not. Observed sporulation is there on the substrate mycelium or not. Also, study chain morphology in respect to spore: rectiflexibilities, spirals or retinaculiaperti $[11,12]$.

\section{Primary screening for antimicrobial activity}

Antimicrobial activity can be detected by using different methods; generally, diffusion of compound or substance in solid or semisolid media and observe the growth of microorganisms which are sensitive to it. By using cross streaking method some advantages of this method like easy to operation and fast results are there. Mainly this method is used for primary screening of cultures in research projects [13].

Zone of inhibition is observed greater in respect to other methods in cross streak techniques while compare with agar well diffusion method. Initial analysis of this type of study cross streak method is choice of interest [14].

So for this in our study here I select cross streak method initially for primary screening of our samples, and I used different 8 pathogens bacteria and checked the zone of inhibition on plates.

Total 66 actinomycetes isolates were used to check for primary screening muller hinton agar media is prepared for this study and streak single loop full of our samples in center of the plates and pathogens streak is done on 90 degrees agle in respect to sample isolate of actinomycetes and incubate our agar plates at $20{ }^{\circ} \mathrm{C}$ for $7 \mathrm{~d}$.

\section{Secondary screening}

These isolates were used in the secondary screening.

In $25 \mathrm{ml}$ conical flask $5 \mathrm{ml}$ of inoculum medium was taken, and inoculums of actinomycetes about $2.5 \%$ were added into media (broth) in aseptic condition. After this procedure flask is incubated at temperature $37{ }^{\circ} \mathrm{C}$ for 7 to $9 \mathrm{~d}$ of duration. By using the centrifugation method at $4000 \mathrm{rpm}$ for $30 \mathrm{~min}$, supernant was obtained. This supernant was used in agar well diffusion method for secondary screening against various pathogens in test [15].

For the evaluation of antimicrobial activity of various plants and microbial extracts agar, well diffusion method is the preferred method of choice. The procedure of this method is similar to the disk diffusion method. First microbes are inoculated on all surface of agar by spreading volume of inoculums of the surface of media. Then after prepared media 6 to $8 \mathrm{~mm}$ diameter hole is made in aseptic conditions by using cork borer which was previously sterile take 20 to $100 \mu \mathrm{l}$ of the volume of an extract of the sample or antimicrobial agent is added with specific concentrations into the hole [16].

Ethyl acetate extract from fermented broth and its antimicrobial properties by disk diffusion method

\section{Extraction of antimicrobial metabolites}

For further study GOS1, JOS1, GOS3, GTF1, and JTF1 this 5 actinomycetes isolates selected.

Take $500 \mathrm{ml}$ Erlenmeyer flask and into flask antibiotic fermentation was done. GOS1, JOS1, GOS3, GTF1, and JTF1 this 5 actinomycetes isolates were incubated using actinomycetes $100 \mathrm{ml}$ of agar medium under aseptic conditions. Then these flasks incubated for $8 \mathrm{~d}$ at $30{ }^{\circ} \mathrm{C}$ with shaking condition. Centrifugation method used to filtrate of fermented mass and by using extraction from this filtrate solvent extraction was carried out for an antibiotic. In ratio 1:1 of volume by volume ethyl acetate added infiltrate. Extraction was done under shaking conditions. Antibiotic-containing ethyl acetate part was separated. Using separating funnel aqueous part was separated. The 
temperature at $40{ }^{\circ} \mathrm{C}$ was used to evaporate and make concentrate this antibiotic containing ethyl acetate extract part. Methanol was used to purification purpose. Using a disk diffusion method check the antibacterial activity of this compound [17].

\section{Thin layer chromatography}

Analysis of ethyl acetate extract was carried out by using thin layer chromatography technique. Thin layer chromatography of crude ethyl acetate extract of fermentation broth of actinomycetes isolates GOS1, JOS1, GOS3, GTF1, and JTF1 was carried out. Antibiotic spots were observed on TLC slide [18].

\section{Bioautography}

It is the method widely used to check, and screening purpose for compounds have antimicrobial activities. To make sure that antimicrobial compound was present of absent in our research work. This method further confirmed any compound have this type of activity or not [19]. TLC method used for separation of the antimicrobial compound in TLC slide. Dried this TLC slide after drying slide was put in petri plate which was previously sterile. 15 ml molten nutrient agar added in plates. Media was sterile before use. Test organisms $2 \%$ added in media and incubated for $24 \mathrm{~h}$ at 37 ${ }^{\circ} \mathrm{C}$. Around the spot in TLC slide zone of inhibition was observed and this proved that the presence of antimicrobial compound [20].

Taxonomic study of most effective antibiotic producer actinomycetes GOS1

\section{Microscopic examination of actinomycetes isolates GOS1}

By using Electron Microscopy GOS1 isolate of actinomycetes, morphology was studied [21].

\section{Cultural characteristics of actinomycetes isolate GOS1}

Cultural characteristics of actinomycetes isolate GOS1 using different media were studied using ISP2, ISP3, ISP4, ISP6, actinomycetes agar, and ISP7.

\section{Biochemical characters of actinomycetes isolate GOS1}

A gram staining was performed to check the grams characteristics of GOS1

\section{Enzymatic activity}

Different enzymatic degradative activities check by two type of incubation method one was spot incubation, and other was streak method. GOS1 actinomycete isolate was incubated in media. Media plate was then incubated for 7 to $8 \mathrm{~d}$ at temperature $30^{\circ} \mathrm{C}[22,23]$.

\section{Utilization of different sugars by Actinomycetes isolates GOS1 was tested}

Utilization of different sugar was observed for actinomycete isolate GOS1. D-glucose, dextrose, sucrose, and maltose utilize very good by GOS1 actinomycete isolate. Ability to utilize D-manitol was observed moderate, and GOS1 actinomycete isolate utilize poorly lactose, L-arabinose, and L-rhamnose while this isolate is not able to utilize Raffinose and d-xylose [24]. Other tests are also performed like indol test, methyl red test, Voges-Proskauer (VP) Test, Citrate test, Hydrogen Sulphide Production test [25].

\section{Sensitivity of Actinomycetes isolates GOS1 against antibiotics}

Actinomycetes isolate GOS1 was prepared by growing culture bennet agar media for at $30{ }^{\circ} \mathrm{C} 48 \mathrm{~h}$. Take $25 \mathrm{ml}$ sterile bennet agar medium in petri plates. The culture of the test was added by swab on the surface of media which was solid in texture. Let them dry for about ten minutes on the surface of this solidified media disk of various antibiotics placed. Around $30 \mathrm{~min}$ time is given at room temperature for better diffusion of placed various antibiotic disks. The incubation time for $48 \mathrm{~h}$ was given at $30^{\circ} \mathrm{C}$. Observe the result whether organism was sensitive for antibiotics of resistance towards those antibiotic $[26,27]$.

\section{Sr DNA sequencing and phylogenic analysis}

While taking about to identify accurately of the bacterial isolate is most important aspect particularly in clinical microbiology labs. Traditional phenotypic way to identify bacterial isolate is very tedious and also more time is required for this in microorganisms which are growing very slowly. Also in this traditional method of phenotypic identification subjective judgment plays a vital role in results [26]. In some species of bacteria among strains variability inn phenotypic characteristics are observed which is specific for identification of the organism. By using all phenotypic tests, there are many parameters remain unidentified in this way. So in this type of conditions, there are $16 \mathrm{~S}$ ribosomal DNA (rDNA) which is based on a molecular approach in identification is give very good results. So here $16 \mathrm{~S}$ ribosomal DNA (rDNA) ribotyping method was used for identification of actinomycete isolate GOS1 up to species level. Amplification of $16 \mathrm{~S} \mathrm{r}$ DNA and sequencing of the amplicon [27]. 16 $S$ rDNA sequence obtained was matched with the nucleotide sequence database present in the National center for biotechnology information (NCBI) by using Blast N program.
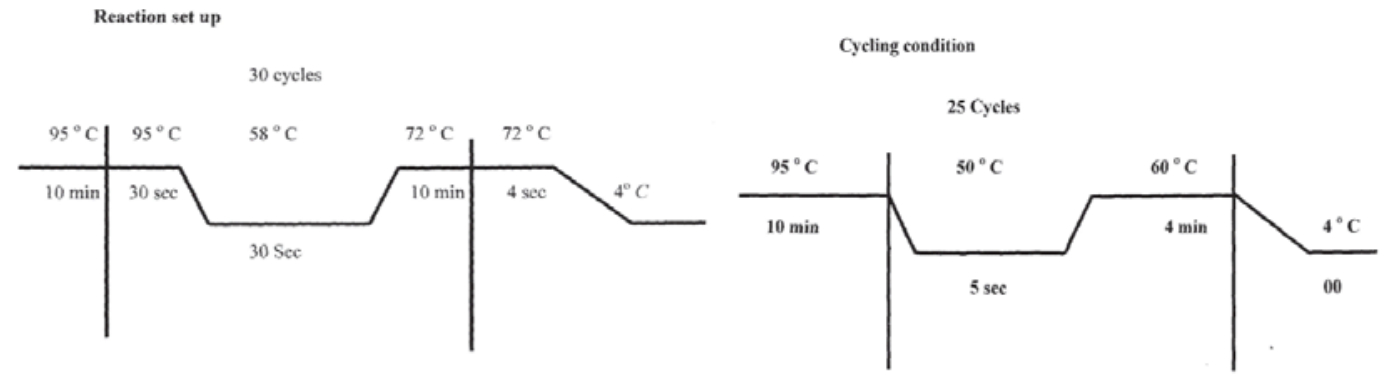

Fig. 2: (A) PCR reaction set up (B) Cycle sequencing reaction

\section{Separation of plasmid for antibiotic production}

In molecular biology field for isolate plasmid DNA or also another component of cell-like protein alkaline lyses method is widely used. In this method lyses means by breaking cell and opening it. In this method first step is to grow the plasmid containing bacteria. And make buffer which is known as alkaline lyses buffer and add bacteria in to it. Buffer contains SDS sodium dodecyl sulfate for detergent action, and sodium hydroxide is used as a base. In cell membrane, there are a protein which was denatured by action of this buffer and phospholipid bilayer of membrane spilt by these detergent properties of the buffer. Also in this method there are so many steps serially like 1 Agitation, 2 Precipitation, and 3 Centrifugation.
Separate supernatant and removed cell debris. By this method, the plasmid was isolated and purified [28].

Agarose gel electrophoresis was performed and checks bands in gel.

\section{Chemicals and reagents}

All cultural media, chemicals, reagents, diagnostic kit used from hi media laboratories, Mumbai, India.

\section{RESULTS AND DISCUSSION}

Based on growth and characteristics of the colony by using 3 different regions of saurashtra and 11 different plant soil samples we found total 66 isolates of actinomycetes. 


\section{Aerial mycelium colors of actinomycetes isolates}

It was found and mentioned in table 1 that actinomycetes isolates from different samples were showing different colors of aerial mycelium like white $(57.58 \%)$, cream (18.18\%), yellow (9.09\%), gray (6.06 \%), brown (4.55\%), pinkish (1.52\%) and bluish (3.03\%).

\section{Vegetative mycelium colors of actinomycetes isolates}

It was found and mentioned in table 1 that actinomycetes isolates from different samples were showing different colors of vegetative mycelium like yellow (48.48 \%), white (18.18\%), cream (12.12\%), brown $(10.61 \%)$, gray $(9.09 \%)$ and reddish $(1.52 \%)$.

\section{Microscopic examination}

Out of 66 actinomycetes isolates, 58 isolates are identified up to genus level by electron microscopy, and table 1 represents the percentage of isolates according to their genus. Previous study of this type of work mentioned that dominant aerial mycelium color was white and vegetative mycelium color was yellow while on identification up to genus level streptomyces genus was 40 percentages [29].

\section{Primary screening for antimicrobial activity}

It was found that out of 66 actinomycetes isolates 45 (68.2\%) actinomycetes isolates were showing activity against test microbes and $21(31.8 \%)$ actinomycetes isolates not showing any activity against test microbes. It was also found that out of 66 actinomycetes isolates 43 (65\%), showed antagonistic activity against Bacillus subtilis, $35 \quad(53 \%)$ showed antagonistic activity against staphylococcus aureus, 29 (44\%) showed antagonistic activity against Proteus vulgaris, 40 (61 \%) showed antagonistic activity against Escherichia coli, 39 (59 \%) showed antagonistic activity against Klebsiella aerogenes, 25 (38 \%) showed antagonistic activity against Pseudomonas aeruginosa, 20 (30\%) showed antagonistic activity against Salmonella typhi, and 22 (33 \%) showed antagonistic activity against Enterobacter aerogenes.

Table 1: Distribution in the percentage of actinomycetes isolates by mycelium color and genus level classification using microscopy

\begin{tabular}{|c|c|c|c|c|c|c|}
\hline S. No. & Colony colors of aerial mycelium & $\%$ & Colony colors of vegetative mycelium & $\%$ & Isolates genus & $\%$ \\
\hline 1 & White & 57.58 & Yellow & 48.48 & Streptomyces & 52 \\
\hline 2 & Cream & 18.18 & White & 18.18 & Micromonospora & 28 \\
\hline 3 & Yellow & 9.09 & Cream & 12.12 & Intrasporangium & 7 \\
\hline 4 & Brown & 6.06 & brown & 10.61 & Saccharopolyspora & 5 \\
\hline 5 & Gray & 4.55 & Gray & 9.09 & Streptosporangium & 3 \\
\hline 6 & Bluish & 3.03 & Redish & 1.52 & Rhodococcus & 3 \\
\hline 7 & Pinkish & 1.52 & - & - & saccharomonospora & 2 \\
\hline
\end{tabular}

Table 2: Distribution of antagonistic activity of actinomycetes zone of inhibition (mm)

\begin{tabular}{|c|c|c|c|c|c|c|c|c|c|c|c|c|c|}
\hline \multirow[t]{2}{*}{ S. No. } & \multirow{2}{*}{$\begin{array}{l}\text { Test } \\
\text { organism }\end{array}$} & \multicolumn{2}{|c|}{ No active } & \multicolumn{2}{|c|}{$>20$} & \multicolumn{2}{|c|}{15 to 20} & \multicolumn{2}{|c|}{10 to 15} & \multicolumn{2}{|c|}{$<10$} & \multicolumn{2}{|c|}{ Total } \\
\hline & & No & $\%$ & No & $\%$ & No & $\%$ & No & $\%$ & No & $\%$ & No & $\%$ \\
\hline 1 & $B s$ & 23 & 34.85 & 8 & 12.12 & 21 & 31.82 & 6 & 9.09 & 8 & 12.12 & 66 & 100 \\
\hline 2 & $S a$ & 31 & 46.97 & 10 & 15.15 & 16 & 24.24 & 3 & 4.55 & 6 & 9.09 & 66 & 100 \\
\hline 3 & $P V$ & 37 & 56.06 & 6 & 9.09 & 8 & 12.12 & 7 & 10.61 & 8 & 12.12 & 66 & 100 \\
\hline 4 & $E c$ & 26 & 39.39 & 6 & 9.09 & 21 & 31.82 & 2 & 3.03 & 11 & 16.67 & 66 & 100 \\
\hline 5 & $K a$ & 27 & 40.91 & 8 & 12.12 & 19 & 28.79 & 3 & 4.55 & 9 & 13.64 & 66 & 100 \\
\hline 6 & $\mathrm{~Pa}$ & 41 & 62.12 & 3 & 4.55 & 11 & 16.67 & 2 & 3.03 & 9 & 13.64 & 66 & 100 \\
\hline 7 & St & 46 & 69.70 & 0 & 0.00 & 10 & 15.15 & 1 & 1.52 & 9 & 13.64 & 66 & 100 \\
\hline 8 & $E a$ & 44 & 66.67 & 0 & 0.00 & 8 & 12.12 & 4 & 6.06 & 10 & 15.15 & 66 & 100 \\
\hline
\end{tabular}

( $B s=$ Bacillus subtilis, $S a=$ Staphylococcus aureus, $P v=$ Proteus vulgaris, Ec = Escherichia coli, $K a=$ Klebsiella aerogenes, $P a=$ Pseudomonas aeruginosa, St $=$ Salmonella typhi, Et $=$ Enterobacter aerogenes $)$

Similar research was done in Chennai, India from a garden soil sample of the university of satyabhama were 13 sample isolates showed activity amongst 22 samples [30]. Also in Madhya Pradesh, India some part of Chambal area hardly 5 samples showed activity amongst 85 isolates [31].

\section{Secondary screening for antimicrobial activity}

15 actinomycetes isolates showed good antimicrobial activity in the primary screening, this top 15 isolates selected for secondary screening for antimicrobial activity by agar well diffusion method.

Table 3: Inhibition in mm of test actinomycetes isolates

\begin{tabular}{|c|c|c|c|c|c|c|c|c|c|}
\hline \multirow[t]{2}{*}{ S. No. } & \multirow[t]{2}{*}{ Isolates code name } & \multicolumn{8}{|c|}{ Microbial species } \\
\hline & & Bs & Sa & Pv & Ec & $\mathbf{K a}$ & $\mathbf{P a}$ & St & Et \\
\hline 1 & GAI1 & $19.67 \pm 0.58$ & $22.67 \pm 1.53$ & 0 & $20.00 \pm 01$ & $18.33 \pm 0.58$ & $19.67 \pm 0.58$ & 0 & 0 \\
\hline 2 & GRI1 & $19.33 \pm 0.58$ & $20.00 \pm 1$ & 0 & $18.00 \pm 1$ & $20.00 \pm 1$ & $19.67 \pm 0.58$ & 0 & $16.67 \pm 0.58$ \\
\hline 3 & GRI2 & $21.67 \pm 0.58$ & $17.33 \pm 0.58$ & 0 & $20.00 \pm 1$ & $20.00 \pm 1$ & $18.67 \pm 0.58$ & 0.00 & $15.33 \pm 0.58$ \\
\hline 4 & JRI1 & $21.00 \pm 1$ & $21.67 \pm 0.58$ & 0 & $20.00 \pm 1$ & $19.33 \pm 0.58$ & $17.00 \pm 1$ & 0 & $18.33 \pm 0.58$ \\
\hline 5 & GOS1 & $27.00 \pm 1$ & $22.00 \pm 1$ & $24.67 \pm 0.58$ & $20.00 \pm 1$ & $26.00 \pm 1$ & 0 & $19.00 \pm 1$ & $18.33 \pm 0.58$ \\
\hline 6 & GOS3 & $20.00 \pm 1$ & $20.33 \pm 0.58$ & $21.33 \pm 0.58$ & $21.00 \pm 1$ & $18.67 \pm 0.58$ & 0 & $19.00 \pm 1$ & $16.00 \pm 1$ \\
\hline 7 & RoS1 & $18.67 \pm 0.58$ & $17.00 \pm 1$ & $18.00 \pm 1$ & $19.00 \pm 1$ & $15.33 \pm 0.58$ & 0 & $17.00 \pm 1$ & $15.00 \pm 1$ \\
\hline 8 & RoS2 & $18.33 \pm 0.58$ & $19.33 \pm 0.58$ & $15.00 \pm 1$ & $17.67 \pm 0.58$ & $17.33 \pm 0.58$ & 0 & $15.67 \pm 0.58$ & $16.67 \pm 0.58$ \\
\hline 9 & JOS1 & $25.00 \pm 1$ & $19.33 \pm 0.58$ & $18.67 \pm 0.58$ & $18.33 \pm 0.58$ & $20.00 \pm 1$ & 0 & $20.00 \pm 1$ & $21.00 \pm 1$ \\
\hline 10 & JAC1 & $17.33 \pm 0.58$ & $2.67 \pm 0.58$ & $19.00 \pm 1$ & $18.33 \pm 0.58$ & $18.33 \pm 0.58$ & 0 & $15.00 \pm 1$ & $16.33 \pm 0.58$ \\
\hline 11 & GTF1 & $18.67 \pm 0.58$ & $20.33 \pm 1.15$ & $22.00 \pm 2$ & $20.00 \pm 1$ & $20.67 \pm 0.58$ & $22.33 \pm 1.15$ & 0 & 0 \\
\hline 12 & GTF2 & $18.67 \pm 0.58$ & $19.33 \pm 0.58$ & $21.00 \pm 1$ & $22.00 \pm 1$ & $20.67 \pm 0.58$ & $19.33 \pm 0.58$ & 0 & 0 \\
\hline 13 & JTF1 & $20.67 \pm 0.58$ & $22.67 \pm 0.58$ & $23.00 \pm 1$ & $20.67 \pm 1.15$ & $21.33 \pm 0.58$ & $20.00 \pm 1$ & 0 & 0 \\
\hline 14 & GPC1 & $18.33 \pm 0.58$ & $19.33 \pm 0.58$ & $18.67 \pm 1.15$ & $19.00 \pm 1$ & $17.67 \pm 0.58$ & $16.00 \pm 1$ & $13.00 \pm 1$ & 0 \\
\hline 15 & JPC1 & $18.33 \pm 0.58$ & $17.67 \pm 0.58$ & 0 & $19.33 \pm 0.58$ & $18.67 \pm 0.58$ & $17.33 \pm 0.58$ & $16.67 \pm 0.58$ & 0 \\
\hline
\end{tabular}

Values are mean $\pm \mathrm{SD}$ of three replications, $(B s=$ Bacillus subtilis, $S a=$ Staphylococcus aureus, $P v=$ Proteus vulgaris, Ec $=E s c h e r i c h i a$ coli, Ka $=$ Klebsiella aerogenes, $P a=$ Pseudomonas aeruginosa, $S t=$ Salmonella typhi, Et = Enterobacter aerogenes) 

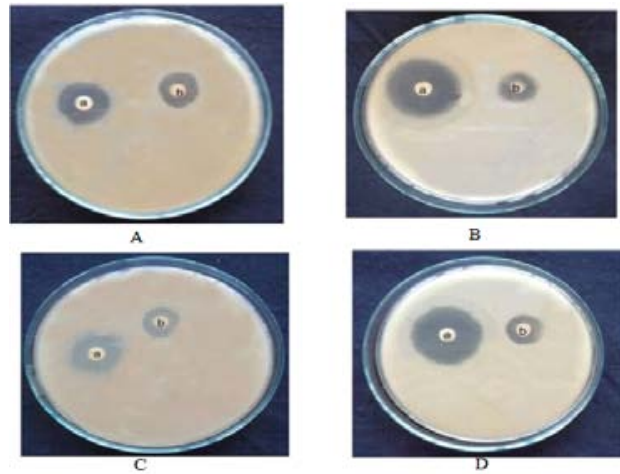

Fig. 3: A (a): GOS3 showed zone of inhibition $21 \mathrm{~mm}$ averse to Escherichia coli, A (b): JOS1 showed Zone of inhibition $20 \mathrm{~mm}$ averse to Escherichia coli, B (a): GOS1 showed zone of inhibition $28 \mathrm{~mm}$ averse to Bacillus subtilis, B (b): JOS1 showed Zone of inhibition $19 \mathrm{~mm}$ averse to Bacillus subtilis, C (a): GOS1 showed zone of inhibition $21 \mathrm{~mm}$ averse to Proteus vulgaris, C (b): JOS1 showed Zone of inhibition $19 \mathrm{~mm}$ averse to Proteus vulgaris, D

(a): GOS1 showed zone of inhibition $26 \mathrm{~mm}$ averse to Staphylococcus aureus, D (b): JOS1 showed zone of inhibition 19 mm averse to Staphylococcus aureus

Out of these 15 actinomycetes isolates 5 isolates GOS1, JOS1, GOS3, GTF1 and JTF1 showing a broad spectrum of activity against microorganisms. It was found that out of this 5 isolates GOS1 was most potent antagonistic actinomycetes. Similar research was done on coastal mangrove area and identifies most potent isolates which may produce antibiotic [32]

Fermented broth of ethyl acetate extract in relation with its antimicrobial activity (Disk diffusion method)

From this observation, it was concluded that the antibacterial compound produced by actinomycetes isolates of five samples was extracted in ethyl acetate and it was further observed that GOS1 actinomycetes isolates were the most potent antibacterial compound producing actinomycetes.

\section{TLC (Thin layer chromatography)}

The actinomycetal isolate GOS3 was showing two separated spots (0.56 and 0.69 Rf);GOS1 was showing a single spot (0.87 Rf) (plate 13);JOS1 was showing two spots (0.8 and 0.69);GTF1 was showing two spots( 0.52 and 0.62$)$, and JTF1 was showing single spot (0.49 Rf). Some study showed that the confirmation of activity by prepared thin layer chromatography plate and make the presence of active samples in Assam and Tripura area of India [33]. Thus it was confirmed that antibiotic was present in ethyl acetate extract and could be separated using butanol: acetic acid: water as the solvent system.

\section{Bioautography}

It was found that GOS1 actinomycete isolate was given the maximum zone of inhibition. So by autobiography zone of inhibition around TLC spot in the plate on agar media confirmed that there is the presence of an antibiotic substance in TLC slide. Averse to different pathogenic microorganisms actinomycetes isolate GOS1 showed a maximum zone of inhibition by primary screening, secondary screening, and bioautography and TLC methods. Also, the properties of antibiotic are remained in ethyl acetate extract was proved. Actinomycete isolate GOS1 may have the ability to produce an antibiotic that was concluded by this research. That's why by observed all result actinomycete isolate GOS1 was used in further study. similar kind of work done in sediments of the bay of Bengal near Srikakulam coast for confirmation of antibiotic activity by secondary screening methods like bioautography [34]

By electron microscopy of actinomycete isolate, GOS1 following characteristics were present.

1 both aerial and vegetative mycelium was present, 2 on aerial mycelium long and spiral chains of spores were observed, 3 spores were circular, 4 smooth surface. By obtaining this observation, actinomycete isolate was confirmed streptomyces species by electron microscopy morphology.

\section{Microscopic examination of actinomycetal isolate GOS1}
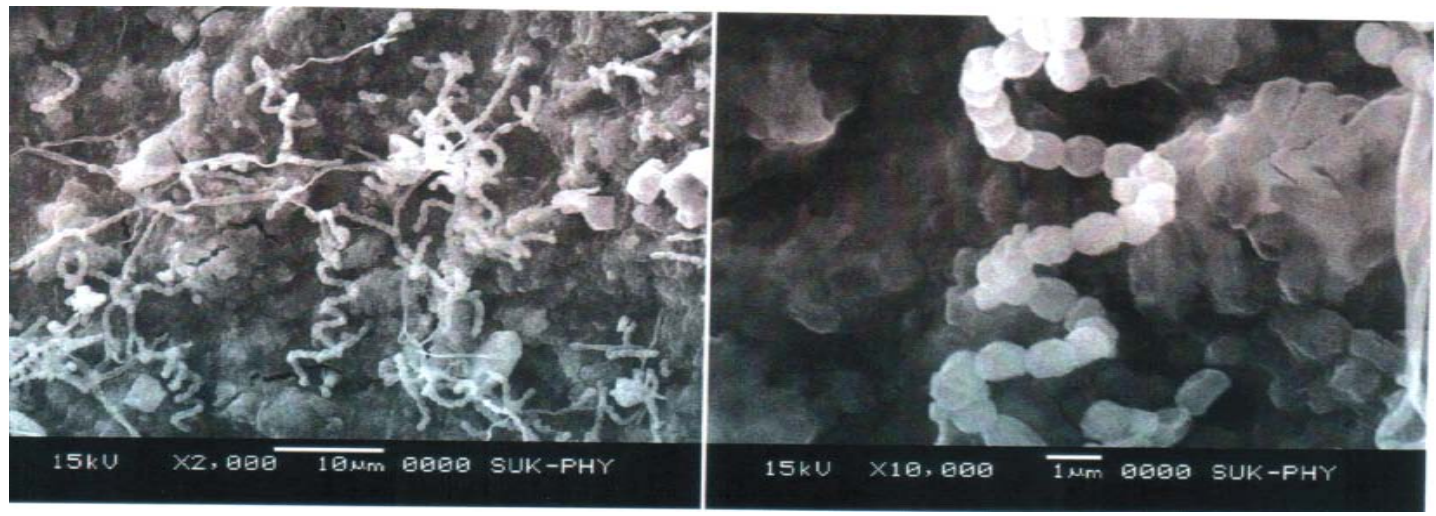

Fig. 4(A): Morphological characters of actinomycetes isolate GOS1 by EM $(\mathrm{x2}, 000)$ (B) Sporulation characters of actinomycetes isolate GOS1 by EM $(x 10,000)$

Cultural characteristics of actinomycetes isolate GOS1

Table 4: Cultural characteristics of actinomycetes isolate G0S1 on different media

\begin{tabular}{lllll}
\hline S. No. & Medium & Growth & Aerial mycelium color & Vegetative mycelium color \\
\hline 1 & ISP2 & Good & White & Bright yellow \\
2 & ISP3 & Good & Cream & Bright yellow \\
3 & ISP4 & Poor & White & Yellow \\
4 & ISP6 & Moderate & Off White & Yellow \\
5 & Actinomycetes agar & Good & White & Pale yellow \\
6 & ISP7 & Moderate & White & Yellow \\
\hline
\end{tabular}


Cultural characteristics of actinomycetes isolate GOS1 using different media were studied. Based on cultural characteristics good growth of actinomycetes isolates was noted on ISP2, Actinomycetes media and ISP3, while the moderate growth of actinomycetes isolates was noted on ISP6 and ISP7 media, and poor growth of actinomycetes isolate was observed on ISP4 media. Also, the white color of aerial mycelium was noted on ISP2, ISP4, ISP7, and Actinomycetes agar media. Cream aerial mycelium color was observed on ISP3 media and off-white aerial mycelium, color was observed on ISP6 media. Previous work on these characteristics was done in turkey from the farming soil samples of actinomycetes isolates [35]. Bright yellow vegetative mycelium color was noted on ISP2 and ISP3 media, pale yellow vegetative mycelium color was observed on Actinomycetes agar media and yellow color of vegetative mycelium was noted on ISP4, ISP6 and ISP7 media.

\section{Grams staining}

Actinomycetes isolate GOS1 was found Gram's positive and showed the violet colour on the slide.

\section{Utilization of different sugars by actinomycetes isolates GOS1} was tested

The capability of Actinomycetes isolates GOS1 to use different sugars was tested. Streptomyces GOS1 was capable to use very good D- glucose, Sucrose, Dextrose and Maltose. Moderate able to utilize Dmannitol. Poorly use L-rhamnose, lactose, and L-Arabinose. Not able to use raffinose and D-xylose.

\section{Enzymatic activity}

It was found that Actinomycetes isolate GOS1 possessing positive results for protease, gelatinase, amylase, lecithinase and cellulose and negative results for urease enzymatic activities. Thus it was found that Actinomycetes isolate GOS1 was mostly enzymatically active. Similar work was done in title identification of antimicrobial actinomycetes Saudi atmosphere [36].

Actinomycetes isolates GOS1 was giving positive test result in $\mathrm{H}_{2} \mathrm{~S}$ production test and methyl red test. Actinomycetes isolates GOS1 was giving negative test result in indol test, vagus Proskauer test, and citrate test

\section{Sensitivity of actinomycetes isolates GOS1 against antibiotics}

Actinomycetes isolate GOS1 was showing sensitivity to linomycin, ciprofloxacin, cifiximine, erythromycin, amoxicillin, tetracycline, penicillin, streptomycin, kanamycin, chloramphenicol and gentamycin but it was showing resistance towards antibiotics cefpodoxime and cephalexin.

Table 5: Enzymatic activity of actinomyces isolate GOS1

\begin{tabular}{|c|c|c|c|c|c|c|}
\hline $\begin{array}{l}\text { S. } \\
\text { No. }\end{array}$ & Enzyme & Medium & $\begin{array}{l}\text { Inc. } \\
\text { method }\end{array}$ & $\begin{array}{l}\text { Inc. period } \\
\text { (days) }\end{array}$ & Criteria of positive enzyme activity & Result \\
\hline 1 & Protease & Modified Beanett agar & Spot & $7-8$ & Clearing around the growth & + \\
\hline 2 & Gelatinase & $\begin{array}{l}\text { Modified Beanett agar with } 0.4 \\
\% \mathrm{w} / \mathrm{v} \text { gelatin }\end{array}$ & Spot & $7-8$ & $\begin{array}{l}\text { Clearing around the growth after flooding with } \\
1.5 \% \text { acidified } \mathrm{HgCl}_{2} \text { solution }\end{array}$ & + \\
\hline 3 & Amylase & $\begin{array}{l}\text { Modified Beanett agar with } 1 \\
\% \mathrm{w} / \mathrm{v} \text { starch }\end{array}$ & Spot & $7-8$ & $\begin{array}{l}\text { Around the growth clearing observed by using } \\
2 \% \text { iodine }\end{array}$ & + \\
\hline 4 & Lecithinase & Egg yolk agar & Spot & $7-8$ & Cloudy zone around the growth & + \\
\hline 5 & Cellulose & Mandel and Reese medium & Streak & $7-8$ & Clearing around the growth & + \\
\hline 6 & Urease & Christenso's agar & Streak & $7-8$ & Development of pink color & - \\
\hline
\end{tabular}

$+=$ Positive; -= Negative
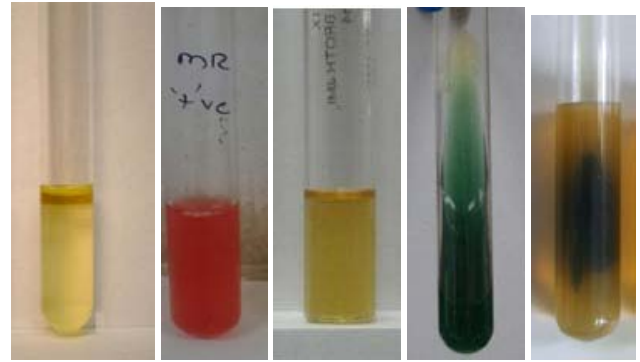

Fig. 5: (A) Indol test result (B) methyl red test result (C) vogus proskauer test result (D) citrate test result (E) Hydrogen sulphide production test result

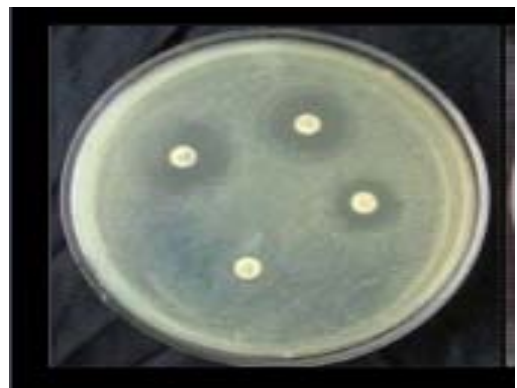

Fig. 6: Antibiotic sensitivity of actinomycetes isolates GOS1 by using different antibiotics
Thus it was found that actinomycete isolate Actinomycetes isolate GOS1 was versatile biochemically and was capable to produce useful antibiotics as of well as many enzymes also. These results were also noted on previous research on the isolation of actinomycetes from soil samples of the forest area of South Africa and check the sensitivity of isolates against pathogens [37].

\section{Sr DNA sequencing and phylogenic analysis}

$16 \mathrm{~S}$ rDNA sequencing revealed that the actinomycetal isolates Streptomyces GOS1 showed close resemblance with Streptomyces arenae, Streptomyces coerulescens, Streptomyces violarus, Streptomyces afghaniensis, and Streptomyces albogriseolus. Cultural, morphological, biochemical characteristics of GOS1 showed close resemblance with Streptomyces arenae. Also, some study mentioned the identification methods of actinomycetes isolates fro soil samples of potent activity against bacteria [38]. Thus Streptomyces GOS1 was confirmed as Streptomyces arenae. Identification of Actinomycetes isolates GOS1 was carried out by16 S r DNA ribotyping.

\section{Separation of plasmid for antibiotic production}

Alkaline lyses method was used for plasmid separation in Streptomyces arenae. There was no plasmid band observed on gel electrophoresis. Plasmid was absent in streptomyces areane.

Thus it was found that antibiotic was the property of the main chromosome and was not plasmid oriented in actinomycetes isolate streptomyces arenae. 


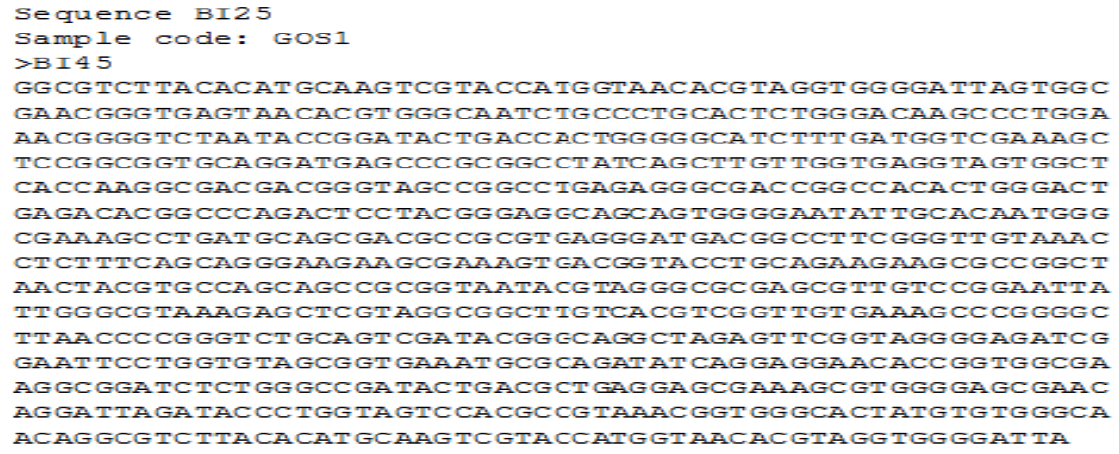

Fig. 7: $16 \mathrm{~S} r$ DNA sequence of actinomycetal isolate streptomyces arenae (771 bases)

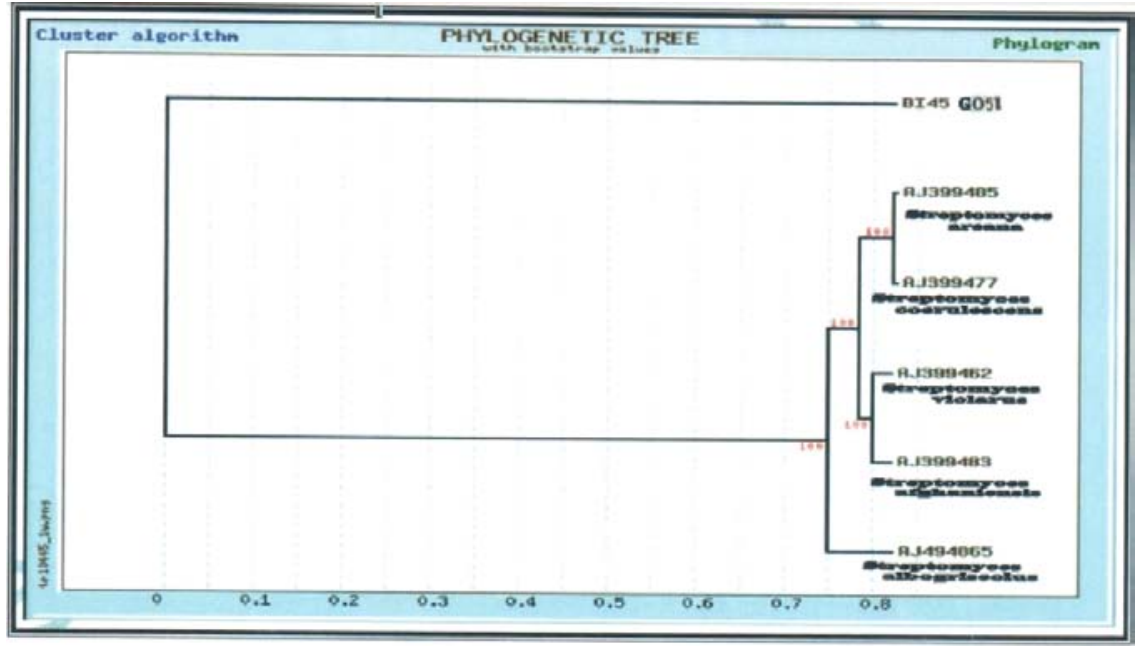

Fig. 8: Phylogenetic tree for actinomycetes isolate GOS1

\section{CONCLUSION}

The present research concluded that actinomycetes from soil surround different medicinal plant area in surashtra region may produce a useful compound which has antimicrobial properties and also there is a chance to develop other industrially important metabolites from them. In this research, GOS1 sample was found most potent, and further in future, there is a chance to produce new and use a full compound which may cause the death of the microbes which has been got resistance. This research will be very useful for the future study for the screening of Actinomycetes from soil and many ecological areas still has not screened for this study.

\section{ACKNOWLEDGMENT}

The author heartily thanks everyone who helped in this research and my guide and mentor Dr. Devang Pandya, who always there to support and guide me in my study.

\section{AUTHORS CONTRIBUTIONS}

Ram Darshit was done experiments and prepared manuscript. Dr. Devang Pandya guides the research work.

\section{CONFLICT OF INTERESTS}

The authors declare that there are no conflicts of interest

\section{REFERENCES}

1. Muharram MM, Abdelkader MS, Alqasoumi SI. Antimicrobial activity of soil actinomycetes isolated from Alkharj, KSA. Int Res J Microbiol 2013;4:12-20.

2. Sreejetha M, Divya, Veena $S$, Kokati VBR. The bioactive potential of streptomycesvariabilis-DV-35 isolated from
Thottada marine sediments, Kannur, Kerala. Asian J Pharm Clin Res 2016;9:67-71.

3. Ramendra Singh Parmar, Charu Singh, Pragati Saini, Ajay Kumar. Isolation and screening of antimicrobial and extracellular pigmentğproducing actinomycetes from chambal territory of Madhya Pradesh region, India. Asian J Pharm Clin Res 2016;9:157-60.

4. Charu Singh, Ramendra Singh Parmar, Pragya Jadon, Ajay Kumar. Characterization of actinomycetes against phytopathogenic fungi of glycine max. Asian J Pharm Clin Res 2016;9:216-9.

5. Mundt JO, Hinkle NF. Bacteria within ovules and seeds. J Appl Environ Microbiol 1976;32:694-8.

6. Mustafa 0, Tamer AU, Cem A. Antibacterial activity of some Actinomycetes isolated from farming soils of turkey. Afr J Biotechnol 2004;3:441-6.

7. Wadetwar RN, Patil AT. Isolation and characterization of bioactive actinomycetes from the soil in and around Nagpur. Int J Pharm Sci Res 2013;4:1428-33.

8. Sivakumar K. Actinomycetes of and Indian. Indian Mangrove (Pichavaram) environment: an inventory. PhD Thesis, Annamalia University, Tamil Nadu India; 2002. p. 91-5.

9. Nanjwade BK, Chandrasekhar S, Goudanavar PS, Shamarez M, Manvi FV. Production of antibiotics from soil-isolated actinomycetes and evaluation of their antimicrobial activities. Trop J Pharm Res 2010;9:373-7.

10. Manjula C, Rajguru P, Muthuselvam M. Screening for the antibiotic sensitivity of free and immobilized actinomycetes isolated from India. Adv Biol Res 2009;3:84-8.

11. Kawato N, R Shinobu. On Streptomyccs herbaricolor, Nov SP supplement: a simple technique for the microscopic observation. Saka Univ Lib Arts Educ J Nat Sci 1959;8:114-9. 
12. Holt JG. Bergey's manual of determinative bacteriology. 9th edition (William and Wilkin Baltimore); 1994. p. 667-9.

13. Sudha Sri Kesavan S, Hemalatha R. Isolation and screening of antibiotic-producing actinomycetes from the garden soil of sathyabama university, Chennai. Asian J Pharm Clin Res 2015; 8:110-4.

14. Williams ST, Cross T. Isolation purification cultivation and preservation of actinomycetes. Methods Microbial 1971;4:295-334.

15. Mounyr Balouiri N, Moulay Sadiki, Saad Koraichi Ibnsouda. Methods for in vitro evaluating antimicrobial activity: a review. J Pharm Anal 2016;6:71-9.

16. C Valgas, SM DeSouza, EFA Smania. Screening methods to determine the antibacterial activity of natural products. Braz J Microbiol 2007;38:369-80.

17. Da Silva, Esquibel MA, Santos JS, Almeida MZ, Sampaino CS, TF Barros. In vitro antibacterial activity of extract from abarema cochliocarpus (Gomes) Barneby and JW Grimes. Afr J Microbiol Res 2010;4:1654.

18. Busti E, Monciardini P, Cavaletti L, Bamote R, Lazarini A, Sosio. Antibiotic producing ability by representatives of a newly discovered lineage of actinomycetes. Acta Microbiol 2006; 152:675-83.

19. Irena M. Choma wioleta Jesionek. J Chrom 2015;2:225-38.

20. Xue Chang Wu Wei, Feng Chen, Chao Dong Qian, Ou Li Ping Li, Yan-Ping Wen. Isolation and identification of newly isolated antagonistic Streptomyces SP Strain AP 192 Producing chromomycins. J Microbiol 2007;45:499-504.

21. Atta HM, SM Dabour, SG Desoukey. Sparsomycin antibiotic production by Streptomyces sp. AZ-NIOF DI: taxonomy fermentation, purification, and biological activities. Am Eurasian J Agric Environ Sci 2009;5:368-77.

22. Deepika L, Kannabiran K. Isolation and characterization of antagonistic actinomycetes from marine soil. J Microbial Biochem Technol 2010;2:1-6

23. Claus DC. A standardized gram staining procedure. World J Microbiol Biotechnol 1992;8:451-2.

24. Murugamani V, Bharathi T, KN Jayaveera. A new antibiotic 105SMP from soil screened Streptomyces species 105-SM. Internet J Microbial 2008;5:1-7.

25. Lakshrnipathy DT, K Kannabiran. A morphological, biochemical and biological studies of halophilic Streptomyces sp. Isolated from saltpan environment. Am J Infectious Diseases 2009;5:207-13.

26. Kavitha R, Dhamodharan N, Dhivya C. Screening, isolation, and antibacterial activity of antibiotic-producing bacteria obtained from saprophytic soil samples. Asian J Pharm Clin Res 2017; 10:92-6.

27. P Saravana Kumar A, V Duraipandiyan B, S Ignacimuthu. Isolation, screening and partial purification of antimicrobial antibiotics from soil streptomyces sp. SCA 7. Kaohsiung J Med Sci 2014;30:435-46.

28. Bernard R Glick, Jack J Pasternak. Molecular biotechnology. Fourth edition. American Society for Microbiology; 2010. p. 125-35.

29. Gurung TD, Sherpa C, Agrawal VP, Lekhak B. Isolation and characterization of antibacterial actinomycetes from soil samples of Kalapatthar, Mount Everest region. Nepal J Sci Technol 2009;10:173-82.

30. Sudha SKS, Hemalatha R. Isolation and screening of antibiotic-producing actinomycetes from the garden soil of Sathyabama University, Chennai. Asian J Pharm Clin Res 2015;8:110-4.

31. Ramendra SP, Charu S, Pragati S, Ajay K. Isolation and screening of antimicrobial and extracellular pigment producing actinomycetes from chambal territory of Madhya Pradesh Region, India. Asian J Pharm Clin Res 2016;9:157-60.

32. Kannan RR, Vincent SG. Molecular characterization of antagonistic streptomyces isolated from a mangrove swamp. Asian J Biotechnol 2011;3:237-43.

33. Thakur D, Yadav A, Gogoi BK, Bora TC. Isolation and screening of Streptomyces in the soil of protected forest areas from the states of Assam and Tripura, India, for antimicrobial metabolites. J Med Mycol 2007;17:242-9.

34. Sujatha P, Swethalatha P. Isolation and screening of novel Streptomyces from sediments of the bay of Bengal near Srikakulam coast. Int J Curr Pharm Res 2016;9:40-4.

35. Oskay M, Tamer AU, Azeri C. Antibacterial activity of some actinomycetes isolated from farming soils of Turkey. Afr J Biotechnol 2004;3:441-6.

36. Saleh MG, Jamal SMS, Amr AMH, Saleh AK, Dina AT, Mohamed MA. Isolation and identification of antimicrobial actinomycetes strain from Saudi environment. J Food Agric Environ 2014;12:1072-9.

37. Muharram MM, Abdelkader MS, Alqasoumi SI. Antimicrobial activity of soil actinomycetes isolated from Alkharj, KSA. Int Res J Microbiol 2013;4:12-20.

38. Abo-Shadi M, Sidkey NM, Al-Mutrafy AM. Antimicrobial agent is producing microbes from some soils' rhizosphere. J Am Sci 2010;6:915-25. 